\title{
A ideologia na produção do espaço: os megaeventos como agentes difusores da ideologia (neo)liberal
}

\author{
Ideology in space production: mega-events \\ as diffusion agents of the (neo)liberal ideology
}

Lucio Hanai Valeriano Viana [l]

\begin{abstract}
Resumo
Esse trabalho tem como objetivo examinar os aspectos ideológicos que permeiam as políticas públicas e sua relação com os espaços urbanos. Para tanto, parte-se da premissa de que os megaeventos, dada a sua magnitude, possuem potencial para atuarem como agentes difusores de modelos urbanísticos. A análise das relações de poder e interesses que direcionam a produção do espaço urbano foi feita com o objetivo de elucidar as características urbanas associadas à realização de megaeventos. 0 trabalho constatou que as estratégias de realização de megaeventos são marcadamente voltadas aos interesses do mercado imobiliário e se apoiam em estratégias mercadológicas amplamente representadas pelo ideário neoliberal.
\end{abstract}

Palavras-chave: modelos urbanos; megaeventos; urbanismo neoliberal.

\begin{abstract}
This work aims to examine the ideological aspects that permeate public policies and their relationship to urban spaces. It is based on the premise that mega-events, given their magnitude, have the potential for acting as diffusion agents of urban models. Relations of power and interests that direct the production of the urban space were analyzed to elucidate the urban characteristics associated with the accomplishment of mega-events. The work found that the strategies to hold mega-events are markedly targeted at the interests of the real estate market and are based on marketing strategies broadly represented by the neoliberal ideology.
\end{abstract}

Keywords: urban models; mega-events; neoliberal urbanism. 


\section{Introdução}

Os eventos de grande porte são conhecidos por renovar e reestruturar as cidades por onde passam. Esse movimento ganhou notoriedade a partir da década de 1960 com a ascensão de políticas urbanas neoliberais ${ }^{1}$ nos países de capitalismo avançado. Nesse período, desenvolveram-se conceitos relacionados ao "empreendedorismo urbano" associados a novas práticas de gestão de cidades (Harvey, 1996).

A realização de megaeventos prevê, entre outras coisas, a revitalização de áreas urbanas degradadas em regiões consideradas com potencial econômico a ser desenvolvido. Essa estratégia de intervenção consiste em transformar espaços públicos e privados para que se tornem atraentes ao capital financeiro, notadamente a especulação imobiliária. Para tanto, novas práticas de gestão foram criadas, Parcerias Público-Privadas (PPPs) ganharam força e conceitos trazidos da administração de empresas passaram a ser incorporados na administração pública (Henry, 1975). 0 surgimento dessa nova dinâmica se baseia na promoção e no financiamento de novos modelos de negócios envolvendo, sobretudo, empresas do setor privado e esferas subnacionais de governo.

0 planejamento estratégico que se seguiu após o período militar no Brasil sofreu fortes influências do cenário internacional em que prevalecia o Consenso de Washington ${ }^{2}$ como receituário para toda e qualquer estratégia de desenvolvimento. Seus efeitos são amplamente conhecidos na América Latina, especialmente pela austeridade fiscal, contenção de gastos públicos, privatizações, abertura e financeirização econômica, entre outros aspectos (Batista Jr, 1994).
Surge, nesse contexto, o conceito de "máquina urbana", cuja finalidade se volta sobremaneira ao atendimento de interesses dos grandes grupos econômicos, que visam a transformar a cidade em uma arena comercial em busca de lucros (Vainer, 2000). Essa prática, pautada na teoria do desenvolvimento, ${ }^{3}$ impõe a dinâmica do capital à administração pública, fazendo, dos instrumentos de gestão, ferramentas de ação a serviço dos grandes investidores. Maricato (2013) ressalta a apropriação do Plano Estratégico Municipal (PEM) ${ }^{4}$ de cidades, utilizado como dispositivo de desregulamentação cuja finalidade se associa diretamente aos interesses privados, notadamente às grandes empresas do mercado imobiliário. Essa forma de gestão impinge às cidades um modelo de concorrência mútuo que contribui para agravar a segregação espacial já conhecida nas metrópoles brasileiras.

Fruto desse contexto, a década de 1990 é marcada pela consolidação do ideário neoliberal nas políticas públicas brasileiras. Trata-se, em larga medida, da implementação estrutural e sistemática de uma forma de gestão cuja racionalidade dissocia o caráter social das relações econômicas. Essa lógica, que se estende aos dias atuais, tende a conceber o desenvolvimento social como resultado espontâneo do crescimento econômico. Contudo, a figuração do País entre as dez primeiras economias mundiais comprovou o distanciamento existente entre crescimento e desenvolvimento. Talvez a expressão mais nítida dessa incongruência esteja na disparidade social existente nos grandes centros urbanos brasileiros.

Apesar da criação de muitos instrumentos de gestão democrática, caso dos Planos Plurianuais (PPs), Planos Diretores (PDs), 
oriundo do Estatuto das Cidades, entre outros mecanismos, o direito urbanístico que visa ao interesse social é relegado a segundo plano. A busca por regularização do uso do espaço urbano em benefício da coletividade parece perder fôlego diante de interesses estritamente econômicos. 0 poder público, em todos os seus níveis de governo, associado aos interesses do capital especulativo e à ideologia (neo) liberal, expõe o ordenamento urbano a toda sorte de possibilidades.

Esse quadro amplamente complexo constitui a práxis urbana de maior parte das metrópoles brasileiras. Essa situação torna-se ainda mais controversa ao se analisar o contexto em que se sucedeu a realização dos megaeventos esportivos no Brasil. Sobretudo ao se constatar a ascensão de um modelo de bem-estar social implementado pelo nível federal de governo a partir da primeira década do século XXI.

Paradoxalmente ao que vem ocorrendo nas grandes metrópoles, o fortalecimento de políticas redistributivas, os programas habitacionais para população de baixa renda, a expansão do sistema público de saúde, entre outras políticas, demonstram certo dualismo do papel desempenhado pelo poder público em suas diferentes esferas. A conquista de certa autonomia dos níveis subnacionais de governo, tendência à descentralização de políticas públicas iniciadas no período pós-Constituição de 1988, tornou mais complexa as análises referentes à gestão pública bem como os seus resultados (Farah, 2006).

$\mathrm{Na}$ conjuntura em que se sucedeu a realização dos megaeventos no Brasil, foi possível observar a proeminência de políticas progressistas, idealizadas notadamente no nível federal, sendo implementadas paulatinamente pelas esferas subnacionais de governo. Em contraste, verificavam-se na gestão local, sobretudo nas grandes metrópoles, conflitos sociais claramente ligados à exclusão social. As desapropriações residenciais de inúmeras famílias, bem como a perseguição ao trabalho informal, ganham notoriedade com a reestruturação urbana requerida pela realização de megaeventos no País.

0 conflito de interesses entre a esfera federal e os níveis subnacionais, especificamente quanto à análise dos megaeventos, revela em larga medida a luta de classes que se expressa no incentivo de práticas de livre-mercado em contraposição às políticas de bem-estar social. Essa realidade é referendada por muitos autores como uma relação de complementaridade entre Estado e mercado e que vem sendo denominada "Keynesianismo neoliberal". 5

No âmbito nacional, são implementadas políticas neokeynesianas, que reconstroem as condições da circulação do capital e da força de trabalho, ao mesmo tempo que subordinam as decisões em torno da utilização dos recursos do fundo público à lógica do mercado e aos interesses dos grandes empresários. Além disso, são adotadas políticas de ativação da demanda efetiva, via a criação e a expansão do crédito ao consumidor, transferência de renda, aumento real do salário-mínimo, etc., expressando políticas redistributivas que incidem sobre as condições de reprodução social. No âmbito local é onde as políticas neoliberais parecem emergir com toda força, resultando no padrão aqui identificado como keynesianismo neoliberal. (Ribeiro e Santos Junior, 2013, p. 28)

Nesse sentido, a realização dos megaeventos parece exprimir uma coalizão de 
interesses distintos estruturada, notadamente, a partir do primeiro decênio do presente século, pelo governo federal. No entanto, a gama de atores envolvidos na realização de eventos de grande porte, bem como suas demandas, acaba por resultar em um novo padrão institucional na esfera local.

Omena (2015) destaca cinco dos nove arranjos institucionais com caráter deliberativo criados em função das Olimpíadas de 2016: Autoridade Pública Olímpica (APO), Empresa Olímpica Municipal (EOM), Companhia de Desenvolvimento Urbano da Região Portuária (CDURP), Comissão de Coordenação dos Jogos (CCJ) e o Comitê Organizador dos Jogos Olímpicos (COJO). Os três primeiros arranjos são governamentais, contudo, nenhum deles possui participação direta da sociedade civil. Essa situação, reflexo da ideologia que permeia os eventos em tela, expõe, institucional e socialmente, o caráter das intervenções urbanas quanto à realização de megaeventos.

De forma geral, eventos dessa magnitude representam uma "janela de oportunidades" para a realização de mudanças estruturais nas cidades. Com o apoio do governo federal e da iniciativa privada, a administração pública local é impelida a acreditar que o sucesso de suas atribuições esteja associado ao atendimento das demandas solicitadas para a realização do evento. Isso ocorre em função das profundas reformas urbanas que acompanham acontecimentos desse porte. Contudo, não é recente a percepção de que o acolhimento das demandas exigidas por eventos de grande envergadura ocorra com valorização do ambiente de negócios empresariais em detrimento dos interesses sociais.
0 Rio de Janeiro, por exemplo, tornou-se um canteiro de obras para a preparação da Copa do Mundo da Federação Internacional de Futebol (Fifa) ${ }^{6}$ e para os Jogos Olímpicos (Rio, 2016). No entanto, a forma e o conteúdo das intervenções urbanas vêm sendo amplamente questionados em função de estratégias socialmente excludentes adotadas pelas autoridades públicas em consenso com dirigentes e instituições internacionais envolvidos no processo.

Há mais de três decênios que as diretrizes e as condicionalidades de organismos e instituições internacionais orientam a gestão pública, em seus diversos níveis, na direção dos fluxos do capital internacional. 0 resultado dessa estratégia se expressa nas diversas formas de atrair investimentos e capitais por meio da exaltação do potencial econômico dos espaços locais. Para essa finalidade, a de tornar as cidades viáveis, vendáveis e seguras aos diversos tipos de investimentos e investidores, são empenhados vultosos volumes de recursos públicos, ainda que negligenciando demandas reais e legítimas dos citadinos locais. Essa lógica costuma contribuir para o aprofundamento das desigualdades socioespaciais na medida em que encarece, sobremaneira, o espaço urbano.

\section{0 mercado global de cidades e o processo de gentrificação}

A estandardização dos espaços como estratégia de atração de investimentos privados costuma ser utilizada também para a promoção de megaeventos. No Brasil, os megaeventos esportivos aconteceram de forma associada a 
projetos urbanos de grande monta, isto é, reformas urbanas vinculadas a projetos de reestruturação de cidades.

A Copa do Mundo Fifa e os Jogos Olímpicos no Brasil, mais especificamente na cidade do Rio de Janeiro, bem como ocorreu em algumas outras nações, identificam-se por sua magnitude e por seu impacto no ambiente urbano. Essa percepção ganha nitidez ao se analisar o orçamento, público e privado, disponibilizado para a realização das obras. As transformações urbanas assumem diversas frentes. Os parques esportivos, necessários para a realização dos Jogos, representam apenas algo necessário para justificar toda a transformação socioespacial incitada pela realização dos megaeventos.

Avalia-se que a articulação de atores e escalas em torno desses projetos tem exigido expressivo investimento simbólico, como instrumento político privilegiado na disputa pelos eventos na busca dos meios necessários à sua atualização e afirmação. Efetivamente, as coalizões de atores (governamentais, privados e de agências internacionais) vinculadas, por exemplo, ao projeto olímpico percebem e se utilizam do megaevento, um espetáculo em escala mundial, para chamar para si a atenção internacional, redirecionar investimentos e amalgamar um novo projeto hegemônico. (Sanchéz, 2010, p. 16)

Assim como destacado por Sanchéz, o campo simbólico combinado aos megaeventos propõe situar as cidades no nível do mercado global, isto é, torná-las atraentes ao capital internacional, ao turismo, aos grandes eventos, entre outros. Nesse sentido, a representação simbólica, somada ao jogo de interesses políticos e econômicos, parece autorizar todo tipo arbitrariedade. Essa percepção tornou-se ainda mais nítida ao se analisar o contexto brasileiro. Vainer (2014) destaca as diversas rupturas para a realização dos Jogos Olímpicos na cidade do Rio de Janeiro: institucional, legal, urbanístico, ambiental, social, entre outras. Nesse sentido, a coalizão de poder engendrada pelos megaeventos consolidou um verdadeiro Estado de exceção no planejamento urbano brasileiro.

Os grupos dominantes associados aos megaeventos, notadamente os rentistas do mercado imobiliário, as grandes empreiteiras, empresas de comunicação e tecnologia, entre outros grandes grupos envolvidos direta e indiretamente na realização do evento, conduziram ações que vislumbraram o sucesso de seus próprios interesses. No que tange ao espaço urbano, a coalização desse grupo de grandes empresas leva necessariamente à elitização das áreas "beneficiadas" pela dinâmica das intervenções. Esse fenômeno costuma provocar transformações sociais, econômicas e espaciais que transcendem a substituição do perfil populacional provocada pelas forças do capital nos espaços físicos da cidade. A substituição da população original por outra de perfil de renda superior costuma ser identificada por gentrificação.

Esse fenômeno, combinado às relações entre capitalismo e espaço urbano, implica forte impacto nas dinâmicas territoriais e populacionais da cidade. Sabe-se que as grandes metrópoles brasileiras tendem a caminhar de forma concomitante à dinâmica capitalista em detrimento das concepções de planejamento urbano. Os Jogos Olímpicos emprestam a ideia de legado urbano às cidades por onde passam, contudo, o chamado legado aparece diretamente associado à dinâmica capitalista de valorização imobiliária e sua consequente 
distorção da organização social urbana. Segundo Santos Junior (2015), o legado atribuído aos megaeventos corresponde a projetos de renovação e reestruturação de cidades. Nessa direção, os megaeventos realizados no Brasil representaram a inauguração de um novo ciclo de mercantilização dos espaços urbanos:

[...] pode-se dizer que se está diante de um novo ciclo de mercantilização da cidade, traduzida na incorporação de determinadas áreas e de serviços urbanos parcialmente desmercantilizados aos circuitos de valorização do capital. Com efeito, percebe-se um processo de elitização da cidade. Esse processo ocorre pela transferência forçada de ativos sob a posse ou controle das classes populares para setores do capital imobiliário. (Ibid., p. 29)

Nesse sentido, é possível apontar a presença das relações capitalistas na disposição do espaço urbano em períodos históricos diversos; daí a ideia de "novo ciclo". A dinâmica capitalista revela-se, em última análise, o ponto crucial para a compreensão do processo de gentrificação. Assim, é preciso analisar as intervenções urbanas relacionadas aos megaeventos de forma complexa levando em consideração as formas de apropriação da mais-valia fundiária e de seus reflexos na dinâmica urbana.

Os ciclos de intervenção no espaço urbano assumem uma polissemia de significados que, nos mais das vezes, ofuscam diversos períodos de mercantilização da cidade, conforme mencionado por Santos Junior. Os processos de renovação, revitalização ou redesenvolvimento de áreas urbanas ganham notoriedade a partir da Segunda Guerra Mundial, com a elevação do desemprego e a necessidade de reconstrução de regiões deterioradas das cidades (Harvey, 2013). Harvey destaca o exemplo da cidade de Nova York:

A deterioração do centro das cidades provocada pela saída de empregos e pessoas gerou então uma forte, e, mais uma vez, subsidiada pelo governo, estratégia de renovação urbana através da demolição e reconstrução de centros urbanos mais antigos [...] o redesenvolvimento metropolitano de Nova York foi capaz de se inserir entre as fontes de fundos públicos e as exigências dos empreendedores privados com um efeito tão forte, refazendo toda a região metropolitana de Nova York por meio da construção de autoestradas e de pontes, do planejamento de parques urbanos e da renovação urbana. (Ibid., p. 72)

Assim, como bem descreveu Harvey, o redesenvolvimento de cidades, vale destacar a forte inversão dos recursos públicos em benefício de setores privados, corresponde às práticas recorrentes no curso histórico. Contraditoriamente, o investimento em infraestrutura urbana tem levado a um processo de desapropriação e remoção de numerosa população. Importante ressaltar que tal processo é realizado, em boa parte dos casos, com autorização e recursos públicos, o que denota a leniência do Estado para com os interesses em jogo.

A tentativa de revitalizar, ou mesmo redesenhar, espaços que, ao longo do tempo perderam dinamismo econômico, indica certa propensão ao fortalecimento das chamadas cidades globais. Segundo Ley (1981), a nova dinâmica do sistema de produção capitalista, sobretudo o processo de acumulação flexível, tende a concentrar profissionais altamente especializados em cidades centrais, isto é, 
aquelas que congregam capitais simbólicos, intelectuais, entre outros atributos.

0 fortalecimento desse tipo de centralidade costuma promover a elitização do espaço e a gentrificação como fenômeno resultante. Desse modo, a reestruturação da hierarquia urbana, promovida por essa nova divisão social, impulsionada pela forma de como são realizados os megaeventos, promove o surgimento de cidades fortemente marcadas pela segregação social. Vale destacar que a estratégia de reestruturação urbana não transforma apenas o aspecto estrutural das cidades, mas também, e sobretudo, das classes sociais, da produção e do consumo nas grandes metrópoles.

Diante desse quadro, a cidade do Rio de Janeiro, no contexto dos megaeventos esportivos, notadamente dos Jogos Olímpicos, destaca-se como objeto de estudo por congregar situações de arranjos políticos, institucionais, burocráticos, econômicos, sociais e culturais que perpassaram pelas mais diversas esferas de governo.

Para além dessa confluência de situações atípicas do ponto de vista da administração pública, as reformas urbanas de grande magnitude costumam ser tratadas como modelos a serem difundidos em outros contextos e regiões.

\section{Difusão de modelos urbanos}

As semelhanças na forma, no conteúdo e também nos discursos delineiam a produção e reprodução do espaço urbano de grandes cidades. $A$ universalidade dos padrões urbanísticos empregados em megaeventos indica a tentativa de amalgamar um projeto hegemônico de urbanização (Sanchéz, 2010).
A discussão está voltada para a questão da constituição e legitimação de paradigmas relativos à reestruturação urbana em escala global. Novos paradigmas, mundializados, que emergem em processos de luta simbólica, são associados às condições históricas e políticas atuais da produção do espaço. Os atores que buscam ocupar posições hegemônicas na enunciação de discursos e na construção de "modelos" procuram impor determinadas categorias de leitura e de representação do urbano, que, por sua vez, influenciam outros atores, em relações transescalares, na definição de estratégias espaciais e na orientação das ações voltadas à produção da cidade-mercadoria. (Ibid., p. 42)

Assim como destacado por Sanchéz, a ideia de replicação de Modelos vem acompanhada de uma série de conceitos e práticas que visam estratégias de negócio, notadamente direcionadas ao conceito de cidade-mercadoria; isto é, orientada para a atender aos interesses do mercado imobiliário e suas interfaces. Assim sendo, os modelos arquitetônicos urbanísticos costumam ser replicados como mera estratégia de negócio. Recomendações de "boas práticas" e modelos de gestão gerencial explicitam o que verdadeiramente se pretende.

No novo cenário mundial que se apresenta no começo do século XXI, a cidade vai se transformando cada vez mais no lugar do negócio financeiro, com operadores mais poderosos e mais incontroláveis do que nunca, que buscam rendimento imediato e um compromisso mínimo com o lugar onde realizam o investimento. Cada cidade é um lugar que pode ser explorado a fim de que contribua com o capital global; certas morfologias urbanas expansivas e dispersas, tipologias arquitetônicas como os arranha-céus e mecanismos neoliberais de gestão são os que 
favorecem esses interesses. (Montaner e Muxí, 2014, p. 21)

Na mesma direção de Sánchez, Montaner e Muxí indicam que a replicação de modelos urbanos consiste, em larga medida, em viabilizar uma estratégia mercadológica pautada na apropriação da mais-valia fundiária de áreas urbanas. Talvez o exemplo mais destacado na literatura sobre a difusão de modelos seja as reformas urbanas ocorridas na cidade de Barcelona, Espanha. A cidade catalã tornou-se um modelo de referência para reformas urbanas de grande magnitude, notadamente no que se refere à realização de Jogos Olímpicos.

Desde 1986, quando a cidade foi escoIhida para sediar as Olimpíadas de 1992, Barcelona passou a realizar intervenções de grande porte. Esse feito transformou as diversas regiões da cidade. Entre os seus idealizadores, destaca-se Joan Busquets, ${ }^{7}$ por suas intervenções urbanísticas de larga escala, isto é, considerando a transformação e a criação de novos espaços completos: ruas, edifícios, praças, parques, escolas e gestão integrada com a iniciativa privada (Capel, 2005).

É curioso notar que uma das principais características do modelo catalão, amplamente difundido como referência de intervenção urbana, destaca as "parcerias público-privadas" (PPPs) como cerne de seu sucesso. Segundo Rolnik:

As chamadas "parcerias público-privadas" (PPPs) estão entre as estratégias de gestão e promoção do desenvolvimento urbano que mais se disseminaram no período recente. Com origem nas cidades norte-americanas nos anos 1980, rapidamente se disseminaram para as cidades do Reino Unido e de outros países europeus, para dali integrar a agenda de capacitação técnica e disseminação de conhecimento dos think-tanks de organismos de cooperação. (2015, p. 226)

Nesse contexto, Rolnik (ibid.) analisa a forma de como as PPPs surgem no campo das políticas públicas. Segundo a autora, as parcerias podem ser caracterizadas como concessões que, conforme o tipo de contrato, transformam-se em privatizações. Ao analisar a ocorrência de práticas de PPPs, a autora destaca a incidência em projetos de modernização de infraestrutura urbana que, por sua vez, alimenta a concepção de competitividade entre os sistemas urbanos. Revela-se, portanto, uma estratégia de negócios associada ao poder público que transforma a cidade em mercadoria.

A experiência de Barcelona tornou-se muito conhecida, sobretudo, pelos resultados econômicos conquistados. As intervenções urbanísticas realizadas na cidade seguem sendo divulgadas e conhecidas como o "Modelo de Barcelona". Contudo, esse projeto urbano pautado, em larga medida, em estratégia turístico-empresarial, vem despertando críticas, muitas delas suscitadas a partir do "urbanismo espetáculo" (isto é, voltado ao marketing de cidades), cuja prioridade das obras buscava causar impacto e visibilidade, relegando as carências sociais a segundo plano.

Segundo Silveira (2007), se a opção tivesse sido sanar os problemas sociais, os custos teriam sido inferiores aos que foram empregados na realização dos megaprojetos voltados ao turismo.

Na década de 1990 houve mudança na orientação das políticas públicas urbanas. A diferença é que na década anterior [1980] os investimentos buscaram 
atender às demandas da população, isto é, aquilo que necessitavam. Prevalecia a presença do setor público. Os empresários, os investidores, os especuladores estavam na expectativa. Ao melhorar a qualidade do ambiente urbano, a cidade se tornou mais atrativa. Na década de 1990, o setor privado passou a ter muita força de intervenção. 0 governo se via endividado em função dos investimentos realizados na década anterior. $E$, quando se investe nas cidades, a preocupação seguinte é mantê-la: os equipamentos, a infraestrutura, etc. Dessa forma, os recursos públicos estavam limitados. 0 setor privado passou a ter força com a dinâmica do mercado. (Borja, entrevista concedida a este pesquisador em 23/6/2016)

Como bem destacou Borja, editor do Plano de Gestão Urbana de Barcelona (19801995), o método de reformulação urbana da cidade possuía como meta prioritária o fortalecimento da competitividade internacional mediante investimentos infraestruturais e o fortalecimento de PPPs. As questões sociais, portanto, seriam sanadas e/ou minoradas, como consequência do crescimento das atividades econômicas genericamente denominadas "mercado". Parece evidente que o pensamento de Borja, bem como no Modelo de Barcelona, está associado à concepção de que as grandes metrópoles necessitam se preparar para uma competição global entre cidades.

Embora essa concepção não se sustente na visão de muitos autores, Capel (2005) destaca a importância da imagem internacional, da "mercadotecnia" (marketing urbano) e do emprego da eficiência econômica por meio do urbanismo e das intervenções nas cidades, bem como ocorreu em Barcelona. Nesse sentido, sua visão converge com a de Borja naquilo que 0 autor considerou um "salto en competitividade internacional" (Borja, 1995, p. 33). Segundo Borja:

[...] las ciudades toman acto de la mundialización de la economía y de la comunicación. En consecuencia se produce una competencia creciente entre territorios y más especialmente entre sus pontos nodales o centros, es decir las ciudades. (p. 276)

Dessa forma, caracteriza-se a concepção de Borja, reiterada por Capel, de que a melhor solução para os problemas enfrentados pelas cidades seria armá-las com eficiência competitiva tal qual uma empresa. Assim, para que essa racionalidade seja viável, faz-se necessária a adoção de mecanismos gerenciais inspirados em melhores práticas (best practices), notadamente aquelas utilizadas no meio empresarial.

Para Borja (ibid.), a adoção de práticas gerenciais veio responder ao que ele definiu por "crisis de las políticas urbanas" e pelo desenvolvimento de best practices precisamente porque se considera que "las grandes ciudades son praticamente ingobernables" (p. 31). Ora, essa ponderação pode ser sustentada apenas do ponto de vista ideológico, pois, na medida em que grandes cidades se tornam ingovernáveis, notadamente em consequência da crise envolvendo as políticas públicas, não se aplica outra forma de governabilidade capaz de resolver o problema.

Segundo Vainer (2000), o fortalecimento de concepções empresariais, bem como o enaltecimento de instituições e organizações internacionais no campo das políticas públicas - notadamente ligadas ao urbanismo -, indica em larga media a tentativa de difundir ideias, conceitos e práticas com a finalidade 
de atender a grupos de interesses específicos, especialmente o grande capital, por meio da especulação imobiliária.

Dificilmente se poderia exagerar quanto à relevância de uma discussão séria e rigorosa deste modelo de planejamento urbano. De um lado, é praticamente total o comprometimento de agências de cooperação e instituições multilaterais em sua difusão e de seus conceitos básicos, de que são exemplos recentes: a) a publicação de alentado volume sobre a experiência de Barcelona, pela Oficina Regional para América Latina e Caribe do Programa de Gestão Urbana, constituído e financiado pela Agência Habitat das Nações Unidas, PNUD e Banco Mundial [Barcelona: un modelo de transformación urbana]; b) a encomenda, feita pela Agência Habitat das Nações Unidas, para que Jordi Borja e Manuel Castells produzissem um documento de análise e propostas especialmente para a Conferência Habitat II (Istambul), em que retomam vários de seus trabalhos anteriores e em que apresentam, para além de análises e propostas, verdadeiras receitas para a aplicação do modelo [Local y global: la gestión de las ciudades en la era de la información]. (Ibid., p. 77; grifos nossos)

Como bem destacou Vainer, a tentativa de difundir o modelo de Barcelona parece evidente. A estratégia econômica por trás do urbanismo espetáculo corresponde à privatização de espaços públicos, isto é, a troca do espaço público pelo espaço privado, que impacta diretamente na arrecadação de receita a partir dos impostos a serem pagos após a intervenção urbana. Vale ressaltar que esse tipo de intervenção, que faz aumentar de forma acelerada os impostos, sobretudo os relacionados à propriedade, constitui estratégia de arrecadação da administração local para recuperar os investimentos empregados ${ }^{8}$ (Silveira, 2007).

Não é sem razão que práticas de mercado são enaltecidas, afinal, o que verdadeiramente parece estar em questão são exclusivamente os interesses de frações específicas de interesses privados. Assim, Borja enfatiza, em seu Programa de Gestão Urbana de Barcelona, que o modelo utilizado correspondeu à aplicação de " técnicas de márketing urbano, de concertación con privados y de concesión de instalaciones. Pero a diferencia de otras situaciones más guiadas por el laissez-faire [...] Barcelona se ha dado con reglas de juego claramente preestablecidas" (Borja, 1995, p. 57).

Nota-se, pois, a forte relação entre o poder público com o setor privado, com nítidas concessões à liberdade econômica que podem ser entendidas por práticas neoliberais - baseada nas linhas do livre mercado -, representada pela terminologia laissez-faire (deixe fazer).

Nesse sentido, Rolnik (2015) destaca a crescente utilização de modelos urbanos inspirados na experiência de Barcelona, sendo disseminados por organismos de cooperação de atuação mundial. Para além da replicação de modelos e práticas gerenciais, a ideologia político-econômica atrelada aos conceitos de intervenção urbana são peremptoriamente neoliberais, uma vez que assumem o livre-mercado como procedimento balizador das estratégias de intervenção urbana.

Apesar de todas as ressalvas, o Modelo de Barcelona, ainda hoje, é considerado uma referência para diversas experiências de planejamento urbano na América Latina, notadamente no que tange à realização de megaeventos esportivos - os Jogos Olímpicos - que 
motivaram as transformações de grande magnitude na cidade catalã.

[...] pode-se observar que o fundamento da formulação de modelos é a identificação de outros com a experiência em questão. Assim, não foi apenas a Inglaterra, [...] mas também a América Latina, que [se inspiraram no modelo de] Barcelona como referência para o planejamento urbano na virada do século. Inspiração para o Rio de Janeiro, Buenos Aires, entre outras capitais, o sucesso de Barcelona afirmou-se com frequência, e estaria ancorado em seu Plano Estratégico. Lançado cerca de 2 anos após a nomeação às Olimpíadas, isto é, quando os destinos da cidade já estavam definidos pela escolha do Comitê Olímpico Internacional, - Plano Estratégico constitui o prenúncio de um trabalho de formalização da experiência de Barcelona, de sua transformação em um modelo. (Lima Jr., 2006, p. 5; grifos nossos)

Como bem destacou Lima Jr., a replicação de um modelo, tal como o em foco, não pode ser justificada nem mesmo se os objetivos fossem os mesmos, pois significaria situações e complexidades idênticas. Em se tratando de políticas públicas, a adoção de modelos torna-se ainda mais complexa, notadamente se levados em consideração os fatores capazes de influenciar e, por vezes, determinar a agenda política, bem como destacou Kingdon (2006).

Ademais, a utilização de modelos em contextos alheios à realidade original poderá gerar resultados negativos ou efeitos colaterais de difícil solução. Assim, Lima Jr. enfatiza:

Transformar uma experiência numa experiência modelar [como no caso da afirmação de Barcelona como referência mundial] pressupõe um trabalho de formalização, ou seja, purificá-la de conteúdos empíricos e considerá-la em suas estruturas formais. $(2006$, p. 5)

Dessa forma, a partir da hipótese de que a replicação de modelos urbanísticos, notadamente a partir da experiência de Barcelona, esteja sendo incentivada e difundida em outros contextos e localidades, analisou-se a experiência da cidade do Rio de Janeiro na realização dos Jogos Olímpicos de 2016.

Sabe-se que a promoção de megaeventos de reconhecimento global tende a se basear em formas e procedimentos padrão para a sua realização. Contudo, em se tratando dos Jogos Olímpicos, o chamado legado urbano vem sendo questionado pela utilização de modelos urbanos preconcebidos baseados em experiências consideradas exitosas. Assim, analisa-se o COI como uma organização capaz de influenciar formas e conteúdos de políticas públicas nas cidades por onde transitam seus eventos.

Desse modo, como bem observou Lima Jr. (ibid.), a adoção de modelos faz-se presente como forma de garantir, ainda que contraditoriamente, bons resultados nas políticas públicas. Contudo, acredita-se, também, que a replicação de modelos esteja associada ao favorecimento de grupos econômicos do setor privado que influenciam a agenda política e dela se beneficiam. Assim, ao apropriar-se de modelos, as organizações internacionais, nas quais se inclui o COI, podem contribuir para replicá-los e impor suas práticas, notadamente a partir do poder e do prestígio que gozam no cenário mundial. 


\section{Modelo urbano e megaeventos}

Baseando-se nas demandas dos megaeventos e aproveitando-se delas para justificar as intervenções urbanas, as cidades passam a adotar modelos urbanísticos voltados aos interesses privados, notadamente, os das grandes empreiteiras de obras públicas ligadas também ao setor especulativo do mercado imobiliário. Essa estratégia, reitera-se, dificulta a permanência da população de baixa renda na localidade onde residem devido ao encarecimento do espaço beneficiado:

A proliferação de empreendimentos imobiliários de alto padrão nas proximidades dos estádios e outras obras emergenciais provocam um duplo processo de expulsão da população mais pobre, seja pela remoção sumária e violenta dos assentamentos, seja pela expulsão "natural" decorrente da forte e nada regulada valorização imobiliária consequente. A Copa e os Jogos, nesse sentido, acirram o nosso apartheid urbano. (Ferreira, 2014, p. 13)

Como destacado por Ferreira, os projetos de intervenção urbana oriundos do contexto dos megaeventos são amplamente questionados em função de seus impactos negativos para a população de baixa renda.

Por conta desse quimérico ideal de sucesso, a população pobre costuma ser afastada dos espaços urbanos beneficiados pela realização dos eventos. Em diversos contextos, a remoção de numerosas famílias ocorre em nome das supostas necessidades urbanísticas vinculadas ao desenvolvimento das cidades. A ideia de reestruturação da cidade atrelada aos megaeventos não é diferente. Ligadas aos interesses do mercado imobiliário, das grandes incorporadoras, das grandes empreiteiras e construtoras, as reformas urbanas, nesse sentido, parecem contribuir para o processo de gentrificação. Isto é, para a realocação de grupos sociais vulneráveis para regiões completamente alheias ao seu contexto.

Apesar das informações nem sempre coincidirem, o Comitê Popular da Copa estima que cerca de 170 mil famílias tenham sido obrigadas a retirar-se de suas casas em função das obras requeridas para a construção de estádios de futebol. 0 argumento costuma ser sempre 0 mesmo, aquele referente à necessidade de desenvolvimento da região (Maior, 2014).

Paradoxalmente, todas as transformações decorrem da retórica do desenvolvimento urbano. Resta saber que conceito de desenvolvimento está associado ao modelo de cidades relacionado aos megaeventos.

A estratégia de legitimação de intervenções urbanísticas pautadas no pretexto do desenvolvimento econômico e social, a partir do investimento do capital privado no espaço urbano, revela a práxis do desenvolvimento relacionada à teoria econômica neoclássica em que figura o desenvolvimento baseado em uma ótica unilateral, isto é, concebida unicamente pelos agentes econômicos. Para Furtado (2008), as decisões eivadas de interesses políticos e ideológicos dificultam o real propósito de ações cujos interesses se relacionam a grupos específicos:

A identificação das forças que estão por trás de toda decisão político-econômica é tanto mais difícil quanto tais decisões vêm sempre cobertas com uma roupagem ideológica, a qual procura desviar a atenção para uma possível ligação entre 
a decisão em causa e o interesse coletivo. (Ibid., p. 35)

Nesse sentido, a especulação imobiliária torna-se o instrumento balizador das intervenções públicas no espaço urbano. Os estudos econométricos que justificam os investimentos em determinadas áreas e locais costumam não levar em consideração as demandas sociais, o que impinge um processo de gentrificação, agravando a vulnerabilidade das camadas mais carentes da população.

Ao analisar cidades que realizaram intervenções urbanísticas decorrentes de megaeventos, Silveira (2007) destaca os altos investimentos direcionados para reformas de infraestrutura que inviabilizam a permanência das classes sociais menos favorecidas nas regiões "beneficiadas" da cidade. Isso se deve em função da elevação do valor dos impostos e, consequentemente, do encarecimento do custo de vida. Segundo o autor, se a opção tivesse sido sanar os problemas sociais, os gastos teriam sido inferiores aos que foram empenhados na realização de produções de megaprojetos. A maneira como as reformas de infraestrutura se dão é uma característica do urbanismo espetáculo no que tange às intervenções urbanas, notadamente aquelas dirigidas à revitalização de espaços em grandes cidades.

A práxis do desenvolvimento urbano ganha maior nitidez nas palavras de Ferreira, ao se analisar a cidade de São Paulo:

Assim, desde já é importante argumentar que a ideologia da "cidade global" paulistana não se assenta em alguma situação virtual, em aparências apenas. Há processos em curso que são fatos, reais e inquestionáveis: o crescimento da oferta de escritórios do setor terciário na região da Marginal Pinheiros, as transformações econômicas ditadas pela financeirização do capitalismo global, por exemplo, são elementos reais e dificilmente questionáveis. Mas a ideologia, como dito, não parte de situações inventadas: assenta-se na realidade, para transformá-la e escamoteá-la para o benefício dos interesses dominantes. (Ferreira, 2003, p. 49)

Como observado por Ferreira, a (re)construção da cidade, para atender aos interesses dos mais diversos segmentos rentistas do mercado mundial, é planejada "por um número significativo de agentes, seja do mercado, da academia e do poder público" que legitimam suas ações em consensos forjados entre frações de classe, criando um modelo de desenvolvimento paradoxal: moderno e ao mesmo tempo conservador.

A padronização das intervenções urbanísticas com a finalidade de atrair investimentos para as cidades, que na verdade oculta a estratégia de venda dos espaços urbanos para grupos de interesse específicos, representa em larga medida a estratégia adotada por diversas cidades do mundo: Paris, BarceIona, Bilbao, Lisboa, Berlim, entre outras. São exemplos de cidades que em algum momento de sua história - em períodos e condições distintos - obtiveram algum êxito em suas estratégias de atendimento aos interesses do mercado mundial. Contudo, nos países de capitalismo tardio, caso do Brasil, a mera reprodução desses modelos contribui para a manutenção do subdesenvolvimento na medida em que agrava a exclusão social e precariza as condições de vida das classes menos favorecidas. Daí o seu caráter conservador.

Ao se estabelecer modelos de intervenção urbanística, adota-se, ao mesmo tempo, 
um padrão único e preconcebido. A adoção de tal estratégia explicita a concentração de poder e influência que detêm os rentistas do mercado imobiliário. Essa prática representa, não apenas o reverso da tendência à descentralização das políticas públicas, justificada pela maior compreensão das necessidades locais, tornando mais eficientes os investimentos públicos e mais legítima a intervenção estatal, como também a consolidação de uma estratégia hegemônica internacional sobre as cidades.

A estratégia adotada para a conquista do direito de sediar dois eventos dessa magnitude implica a coalizão de diversos interesses. No campo político-ideológico, privilegiaram-se grupos econômicos de poder hegemônico direta e indiretamente ligados à viabilidade dos eventos. Destacam-se as grandes empreiteiras de obras públicas responsáveis por estruturar as cidades, notadamente as vias de acesso. A mobilidade urbana corresponde a um dos fatores mais importantes para o sucesso dos eventos e costuma estar associada ao chamado legado. As construtoras do setor hoteleiro, intimamente ligadas à estratégia de reestruturação urbana, compõem o grupo de poder ligado à construção civil. As empresas de entretenimento e comunicação, representantes dos interesses desses grandes grupos, atuam de forma transversal, buscando vender os eventos como algo benéfico ao conjunto da sociedade. Vale destacar que o espetáculo midiático constitui ferramenta fundamental para o sucesso dos negócios.

Essa conjuntura, circunstanciada pela realização dos Jogos no Brasil, destaca de forma veemente a importância do setor privado para o sucesso de ambos os eventos. Assim, como uma espécie de solução a todos os desafios colocados em pauta pelos megaeventos, a lógica privada e privatista passa a ser aplicada ao setor público.

0 conceito de cidade, e com ele os conceitos de poder público e de governo da cidade são investidos de novos significados, numa operação que tem como um dos esteios a transformação da cidade em sujeito/ator econômico [...] e, mais especificamente, num sujeito ator cuja natureza mercantil e empresarial instaura o poder de uma nova lógica, com a qual se pretende legitimar a apropriação direta dos instrumentos de poder público por grupos empresariais privados. (Vainer, 2000, p. 89)

Dessa forma, o discurso da suposta eficácia e eficiência na administração pública passa a ser construído associando políticas públicas às boas práticas gerenciais (best practices). Privatizações de empresas e espaços públicos, PPPs, entre outras medidas, passam a fazer parte da concepção da assim chamada "boa gestão" (Paula, 2005). Empresta-se a ideia de modernidade à transferência de responsabilidades públicas ao setor privado. Essa prática é construída não apenas de forma discursiva, mas também por meio de mecanismos que conciliam o discurso às imagens representantes do moderno. Daí a necessidade da arquitetura arrojada e ultrafuturista que simboliza os megaeventos. A superexposição do "moderno" costuma ser amplamente utilizada pelas empresas de comunicação que centram as suas estratégias comerciais em merchandising e em outros produtos que lhe permitem oportunidades de negócio.

Assim, o discurso do moderno ligado ao modus operandi da gestão pública vai ganhando legitimidade. Vainer (2000) denuncia 
o processo, real e simbólico, para que a transformação do espaço urbano ocorra de forma consensual por meio de estratégias discursivas. Esse proceder, articulado com os grandes empresários envolvidos nos eventos, constrói a ideia de que toda e qualquer transformação urbana que esteja a serviço dos megaeventos deva ser aceita e bem-vinda pela sociedade. Nesse sentido, as transformações oriundas dessa construção político-ideológica parecem dar legitimidade às remoções de inúmeras famílias residentes em áreas destinadas para projetos de megaeventos. A privatização de espaços públicos bem como a sua elitização também passam a ser concebidas como uma consequência natural do progresso. Essa lógica explica, em certa medida, a naturalização da exclusão social, aqui representada pelos processos gentrificadores, motivados pela realização de megaeventos.

0 poder das representações está em sua presença material, literalmente solidificada na arquitetura e no urbanismo. As geografias da "gentrificação" são geradas por processos materiais, mas também pelos simbólicos. Os idealizadores, planejadores e profissionais do marketing atuantes nesses processos simbólicos codificam as formas construídas em códigos para receptores que irão reinterpretá-los. (Sánchez, 2010, p. 111)

Como bem destacou Sánchez, o campo simbólico assume considerável importância no contexto em que a valorização do produto megaevento - combina a ideia de sucesso ao status de poder e de prestígio. Nesse sentido, quanto maior a percepção do consumo, bem como a seletividade do público por critério de renda, maior será a sensação de triunfo e êxito.
Portanto, quanto mais seletivo, disputado e cobiçado for o acesso aos megaeventos, mais forte será a hegemonia dessa concepção de cidade pautada na exclusão social.

\section{Notas conclusivas}

Constatou-se que a realização de megaeventos transcende as suas fronteiras. 0 chamado "legado" para as cidades corresponde, em larga medida, às transformações urbanas que pouco se relacionam ao evento. Além disso, ao se constatar certa padronização das políticas públicas urbanas, perceberam-se, com maior nitidez, os interesses econômicos dos grandes grupos envolvidos no processo.

0 Modelo de Barcelona destaca-se como referência em vários aspectos. 0 primeiro, e talvez mais importante, seja o incentivo ao fortalecimento de parcerias público-privadas nas políticas públicas. Essa orientação enaltece a importância de empresários do setor privado nas políticas públicas, tornando-as suscetíveis às suas influências e interesses. A literatura identifica as PPPs, notadamente no que tange aos megaeventos, como um dos caminhos pelos quais ocorre o empresariamento das cidades, isto é, a privatização de espaços públicos e o fortalecimentos de estratégias de valorização imobiliária.

De forma sintética, averiguou-se que o incentivo às práticas gerenciais voltadas ao custo-benefício, bem como a difusão de modelos urbanísticos considerados exitosos, resulta em políticas que induzem ao encarecimento do solo urbano e, por conseguinte, ao processo de gentrificação. 
Por fim, as estratégias de planejamento urbano atreladas à realização de megaeventos aparecem diretamente associadas ao conceito de cidade-mercadoria, fortemente pautado no ideário (neo) liberal.

\section{[I] https://orcid.org/0000-0002-0805-6995}

Grupo Ibmec/Wyden, São Paulo, SP/Brasil.

Observatório das Metrópoles, núcleo São Paulo. São Paulo, SP/Brasil. luciohanai@hotmail.com

\section{Notas}

(1) O significado do conceito de neoliberalismo, amplamente utilizado na literatura que analisa as doutrinas político-econômicas, está associado à crença de que as forças que operam nas mais diversas relações econômicas são capazes de autorregulação. O prefixo "neo" (novo) costuma distinguir o novo liberalismo por acreditar na importância do Estado como agente garantidor da livre-concorrência. Na atualidade, o termo costuma ser utilizado para indicar a livre atuação das forças do mercado, a abertura econômica e privatizações de empresas e serviços públicos (ver mais em: Sandroni, 2008).

(2) Segundo Couto (2002, p. 73), o Consenso de Washington pode ser assim definido: um conjunto de preceitos a serem seguidos pelos países em desenvolvimento para realizar as suas reformas econômicas. São diretrizes de referencial neoliberal cuja ênfase se concentra na economia de mercado. De modo geral, o Consenso de Washington caracteriza-se pela abertura econômica, desregulamentação, rígido controle da inflação e do déficit público, redução do tamanho e do papel do Estado e privatizações.

(3) A teoria do desenvolvimento está fortemente orientada na crença de que o aumento do nível de atividade econômica gera, por si mesmo, desenvolvimento social. Schumpeter já havia destacado o limite dessa concepção teórica ao afirmar que "Nem o mero crescimento da economia, representado pelo aumento da população e da riqueza, será designado aqui como um processo do desenvolvimento" (1978, p. 63). A distinção entre crescimento econômico e desenvolvimento foi profundamente analisada, notadamente no tocante à América Latina, por Celso Furtado em sua vasta obra sobre a temática do subdesenvolvimento.

(4) Vale ressaltar que o PEM integra e concilia o Plano Diretor Municipal (PDM) e o Plano Plurianual Municipal (PPM) às políticas públicas. Constitui, portanto, um importante instrumento de gestão capaz de articular estratégias e ações entre a sociedade civil e as esferas de governo: federal, estadual e municipal. 
(5) John Maynard Keynes é reconhecidamente um dos mais importantes economistas do século XX. Sua principal obra, The General Theory of Employment, Interest and Money (A Teoria Geral do Emprego, do Juro e da Moeda), teve repercussão prática ao analisar a Crise de $1929 \mathrm{em}$ que a bolsa de valores norte-americana sofre forte depressão. A ideia diretora dessa obra corresponde à constatação de que o mercado, notadamente em sua prática liberal (livre), não é capaz de autorregular-se. Isto é, o mercado pode sobreviver com elevadas taxas de desemprego e, ainda assim, estar em equilíbrio. Dessa forma, Keynes constata que o desemprego é fruto da insuficiência de investimentos na economia, cabendo ao Estado induzir e promover os investimentos necessários. Ver: Keynes,1996).

(6) O site virtual da instituição utiliza a nomenclatura em francês: Fédération Internationale de Football Association (Fifa). Essa federação, fundada em no dia 21 de maio de 1904 em Paris, atualmente com sede em Zurique na Suíça, dirige as associações de futebol, futsal e o futebol de praia. Vale destacar que a Fifa está filiada ao Comitê Olímpico Internacional (COI) e congrega 209 organizações esportivas nos mais diversos países.

(7) Joan Busquets dirigiu o Departamento de Planejamento do Município de Barcelona, entre 1983 e 1989, e foi Coordenador de Urbanismo durante os preparativos para as Olimpíadas em 1992.

(8) Essa mesma situação, de valorização imobiliária resultando em processo de gentrificação, ocorreu também na cidade do Rio de Janeiro. É uma de muitas características que se assemelham ao Modelo de Barcelona.

\section{REFERÊNCIAS}

BATISTA JR., P. N. (1994). O Consenso de Washington: a visão neoliberal dos problemas latinoamericanos. Disponível em: http://www.consultapopular.org.br/sites/default/files/consenso\%20 de\%20washington.pdf . Acesso em: 30 maio 2017.

BORJA, J. (1995). Barcelona: un modelo de transformación urbana 1980-1995. Programa de Gestão Urbana - PGU - Oficina Regional para América Latina y el Caribe. UNCHS, PNUD, Banco Mundial, GTZ.

CAPEL, H. (2005). El modelo de Barcelona: un examen crítico. Barcelona, Ediciones del Serbal.

COUTO, R. C. (2002). A História Viva do BID e o Brasil. Rio de Janeiro, Banco Interamericano de Desenvolvimento.

FARAH, M. F. S. (2006). Temas emergentes em gestão e políticas públicas: tendências gerais. Cadernos Gestão Pública e Cidadania, n. 48, pp. 43-66.

FERreirA, J. S. W. (2003). São Paulo: o mito da cidade-global. Tese de Doutorado. São Paulo, Universidade de São Paulo.

FURTAdo, C. (2000). Teoria Política do Desenvolvimento Econômico. (1 ed. 1973). São Paulo, Paz e Terra. 
FURTADO, C. (2008). Economia do desenvolvimento - Curso ministrado na PUC-SP em 1975. Arquivos Celso Furtado. Rio de Janeiro, Contraponto. Centro Internacional Celso Furtado de Políticas para o Desenvolvimento.

HARVEY, D. (1996). Do gerenciamento ao empresariamento: a transformação da administração urbana no capitalismo tardio. Espaços \& Debates. São Paulo, n. 39, pp. 48-64.

(2013). Condição Pós-Moderna. São Paulo, Loyola.

HENRY, N. (1975). Paradigms of public administration. Public Administration Review, v. 35, n. 4, pp. 378-386.

KEYNES, J. M. (1996). Teoria Geral do Emprego, do Juro e da Moeda. São Paulo, Nova Cultural.

KINGDON, J. W. (2006). “Como chega a hora de uma ideia?”. In. SARAIVA, E. e FERRAREZI, E. Políticas Públicas: Coletânea. Brasília, Enap, v. 1, pp. 219-223.

LEY, D. (1981). Inner city revitalization in Canada: a Vancouver case study. Canadian Geography, n. 25. Vancouver.

MAIOR, J. L. S. (2014). "Lei geral da Copa: explicitação do estado de exceção permanente". In: Brasil em jogo: o que fica da Copa e das Olimpíadas?. Rio de Janeiro, Boitempo.

MARICATO, E. (2013). Brasil, cidades: alternativa para a crise urbana. Petrópolis, Vozes.

MONTANER, J. M. e MUXÍ, Z. (2014). Arquitetura e Política: ensaios para mundos alternativos. Barcelona, Gustavo Gili.

LIMA Jr., P. N. (2006). Apontamentos sobre o trabalho teórico para afirmar Barcelona como um modelo de planejamento. In: X COLÓQUIO INTERNACIONAL SOBRE PODER LOCAL. Anais... Salvador, pp. 1-10.

OMENA, E. (2015). "A 'Copa das Manifestações' e os Processos de Governança Urbana no Brasil”. In: SANTOS JUNIOR, O. A; GAFFNEY, C. e RIBEIRO, L. C. Q. (orgs.). Brasil: Os impactos da copa do mundo 2014 e das olimpíadas 2016. E-papers. Rio de Janeiro, Observatório das Metrópoles.

PAULA, A. P. P. (2005). Administração Pública Brasileira entre o gerencialismo e a gestão social. Revista de Administração de Empresas - RAE, v. 45, n. 1.

RIBEIRO, L. C. de Q. e SANTOS JUNIOR, O. A. dos (2013). Governança Empreendedorista e Megaeventos Esportivos: reflexões em torno da experiência brasileira. O Social em Questão, n. 29.

ROLNIK, R. (2015). Guerra dos lugares: a organização das terras e da moradia na era das finanças. São Paulo, Boitempo.

SÁNCHEZ, F. (2010). A reinvenção das cidades para um mercado mundial. Chapecó, Argos - Editora da Unochapecó.

SANDRONI, P. (2008). Dicionário de Economia do Século XXI. Rio de Janeiro, Record.

SANTOS JUNIOR, O. A. dos (2015). “Metropolização e Megaeventos: proposições gerais em torno da Copa do Mundo 2014 e das Olimpíadas 2016 no Brasil". In: SANTOS JUNIOR, O. A; GAFFNEY, C. e RIBEIRO, L. C. Q. (orgs.). Brasil: Os impactos da copa do mundo 2014 e das olimpíadas 2016. E-papers. Rio de Janeiro, Observatório das Metrópoles.

SCHUMPETER, J. (1978). The Theory of Economic Devefopment. Oxford, Oxford University Press. 
SILVEIRA, C. E. R. (2007). Processos de gentrificação: a (re)organização espacial nas cidades, a construção de territórios e a questão do espaço como um sistema informacional. In: VIII ENANCIB - Encontro Nacional de Pesquisa em Ciência da Informação, 28 a 31 de outubro. Salvador, Bahia.

VAINER, C. (2000). "Pátria, empresa e mercadoria". In: ARANTES, O.; VAINER, C. e MARICATO, E. (orgs.). A cidade do pensamento único: desmanchando consensos. Petrópolis, Vozes.

(2014). “Como serão nossas cidades após a Copa e as Olimpíadas?”. In: Rolnik, R. et al. Brasil em jogo: o que fica da Copa e das Olimpíadas? Rio de Janeiro, Boitempo/Carta Maior.

Texto recebido em $1 \%$ dez/2018

Texto aprovado em 19/dez/2018 